\title{
Carrier detection in Duchenne muscular dystrophy
}

\author{
J S FITZSIMMONS, J I McLACHLAN, W G REEVES, D W MARRIOTT, \\ A M J WOOLFSON, AND J MAYHEW \\ From the Genetic Counselling Service, and Department of Clinical Chemistry, City Hospital, Nottingham; \\ and Department of Immunology, University Hospital, Nottingham
}

SUMMARY Serum creatine kinase, myoglobin, and percentage lymphocyte capping was determined in ten patients with Duchenne muscular dystrophy, 12 carriers (nine definite and three probable), 16 other female relatives, and eight normal controls. There was no detectable difference in lymphocyte capping ability between any of these clinical groups. Significant myoglobinaemia was present in all the affected males, but the difference in levels between carriers and controls suggested that this test has no advantage over creatine kinase estimations in carrier detection.

Despite recent reports of membrane abnormalities in patients with Duchenne muscular dystrophy (DMD) ${ }^{1-4}$ estimation of serum creatine kinase (SCK) has remained the most popular and, so far, the most reliable means of carrier identification. ${ }^{5}$ However, this test is far from ideal and not all definite carriers have raised levels. Even with early investigation of those at risk $^{6}$ only 70 to $75 \%$ of carriers have abnormal values. There was considerable interest, therefore, in reports by Verrill et $a l^{7}$ and later by Pickard $e t a l^{8}$ of impaired lymphocyte capping in patients with this disease. They suggested that as a consequence of altered membrane fluidity of $\mathbf{B}$ lymphocytes there was a reduction in the aggregation of surface immunoglobulin after incubation with fluorescein-labelled antiglobulin, the so-called capping phenomenon. These changes were reported in carriers as well as in patients and were noted in other muscular dystrophies. The difference in the degree of capping was sufficiently marked to suggest that this test, if confirmed, would be extremely valuable in counselling families with Duchenne muscular dystrophy. 910

An earlier paper by Adornato et al ${ }^{11}$ reported myoglobinaemia in some patients with this disease and suggested that this was also a consequence of membrane changes in muscle plasmalemma. There were 18 patients in the families studied and 14 of these had detectable serum myoglobin levels in the range 0.2 to $3 \mu \mathrm{g} / \mathrm{ml}$ (mean $0.79 \mu \mathrm{g} / \mathrm{ml}$ ). Ten of 16 carriers including four with normal SCK values had demonstrable myoglobinaemia (mean $0.75 \mu \mathrm{g} / \mathrm{ml}$ ) but none was detected in the 22 control women (SI units $=\mu \mathrm{g} / \mathrm{ml} \times 10^{-3} \mathrm{~g} / \mathrm{l}$ ). The authors con-

Received for publication 18 July 1979 cluded that this assay, in conjunction with SCK estimation, was a useful adjunct in carrier detection.

This study set out to evaluate each of these three investigations, that is, SCK, myoglobin, and lymphocyte capping, in patients with Duchenne muscular dystrophy and their families attending the Genetic Counselling Clinic in Nottingham.

\section{Subjects}

There were 12 families with ten affected males. The patients had unequivocal clinical, pedigree, and biochemical evidence of DMD. In all but two there was additional confirmation of the diagnosis from muscle biopsy specimens and electromyography.

Nine females were classified as definite carriers having (1) a son with DMD and a male relative with the disease, or (2) two or more sons with the disease, or (3) raised serum creatine kinase plus an affected son or an affected male relative.

Three females were classified as probable carriers having an affected son, no other affected relatives, and a previously unknown SCK level.

Sixteen female relatives other than those described above were listed as possible carriers.

There were eight normal controls, who were unrelated fathers of affected children.

\section{Methods}

\section{SPECIMENS}

All specimens were collected between 8.00 am and 9.30 am and lymphocyte studies were performed the same day. The subjects were asked to refrain from unusual exertion for 48 hours before venepuncture. Blood for myoglobin and SCK estimations 
was collected into plain glass tubes. The serum was separated within 4 hours and stored at $-20^{\circ} \mathrm{C}$ until analysis.

All blood specimens were coded before arrival in each laboratory and the clinical category of each specimen was unknown to anyone involved in the laboratory work.

\section{LYMPHOCYTE CAPPING}

Firstly $5 \mathrm{ml}$ blood was admixed with 20 units $/ \mathrm{ml}$ preservation-free heparin and incubated with $10 \mu 1$ of a $5 \%$ latex suspension $(0.8 \mu$, Difco Laboratories). This mixture was incubated for 30 minutes at $37^{\circ} \mathrm{C}$. Mononuclear cells were then separated on Ficoll isopaque Lymphoprep (Nyegaard and Co) by centrifugation at $800 \mathrm{~g}$ for 15 minutes. The lymphocyte layer was washed three times with RPMI 1640 culture medium containing $5 \%$ fetal calf serum. Then $1 \times 10^{6}$ cells were added to $20 \mu l$ of fluoresceinlabelled reagent (polyvalent anti-Ig monospecific anti-IgM, Wellcome Reagents Ltd) which had been previously dialysed overnight against phosphate buffered saline to remove the azide preservative. The cells were incubated at $4^{\circ} \mathrm{C}$ for 60 minutes in the dark before being washed at $4^{\circ} \mathrm{C}$ before incubation for up to 60 minutes at $37^{\circ} \mathrm{C}$. The cells were then washed with phosphate buffered saline containing $4 \%$ paraformaldehyde and mounted.

Slides were viewed in a Leitz SM-LUX microscope using both incident broad-band blue light (fluorescein excitation) and transmitted white light from a tungsten source. All cells containing latex particles, for example, monocytes or neutrophils, were disregarded and a total of at least 100 fluorescent cells were counted per slide. Cells were regarded as having reached the capping stage when at least $75 \%$ of the surface fluorescence was confined to one hemisphere. These cells were expressed as a percentage of the total fluorescent cells.

\section{SER UM MYOGLOBIN}

Serum myoglobin was estimated by a radioimmunoassay technique slightly modified from that recommended by International CIS ${ }^{\mathrm{R}}$. The procedure was essentially that suggested by the manufacturers with omission of the PEG washing step. The normal range adopted was 10 to $85 \mathrm{ng} / \mathrm{ml}$ (SI units= $\left.\mathrm{ng} / \mathrm{ml} \times 10^{-6} \mathrm{~g} / \mathrm{l}\right)$.

\section{SERUM CREATINE KINASE}

SCK was estimated by the Calbiochem ${ }^{R}$ StatPack ${ }^{\mathrm{TM}}$. Assays were performed at $30^{\circ} \mathrm{C}$ using a Gilford 300-N recording spectrophotometer. The volumes used were $3 \mathrm{ml}$ mixed reagent and $100 \mu \mathrm{l}$ serum. Expected values were female 5 to $50 \mathrm{IU} / 1$; male 3 to $80 \mathrm{IU} / 1$.

\section{Results}

In fig 1 the percentage capping in each of the clinical categories shows no significant difference between the various groups. These data were derived for IgM bearing B lymphocytes. Fig 2 shows the results obtained when a capping technique closely resembling that of Pickard et $a^{8}$ (detecting both $B$ and $L$ cells) is compared with the $\operatorname{IgM}$ B cell assay. A close correlation is seen but neither assay discriminated between patient groups.

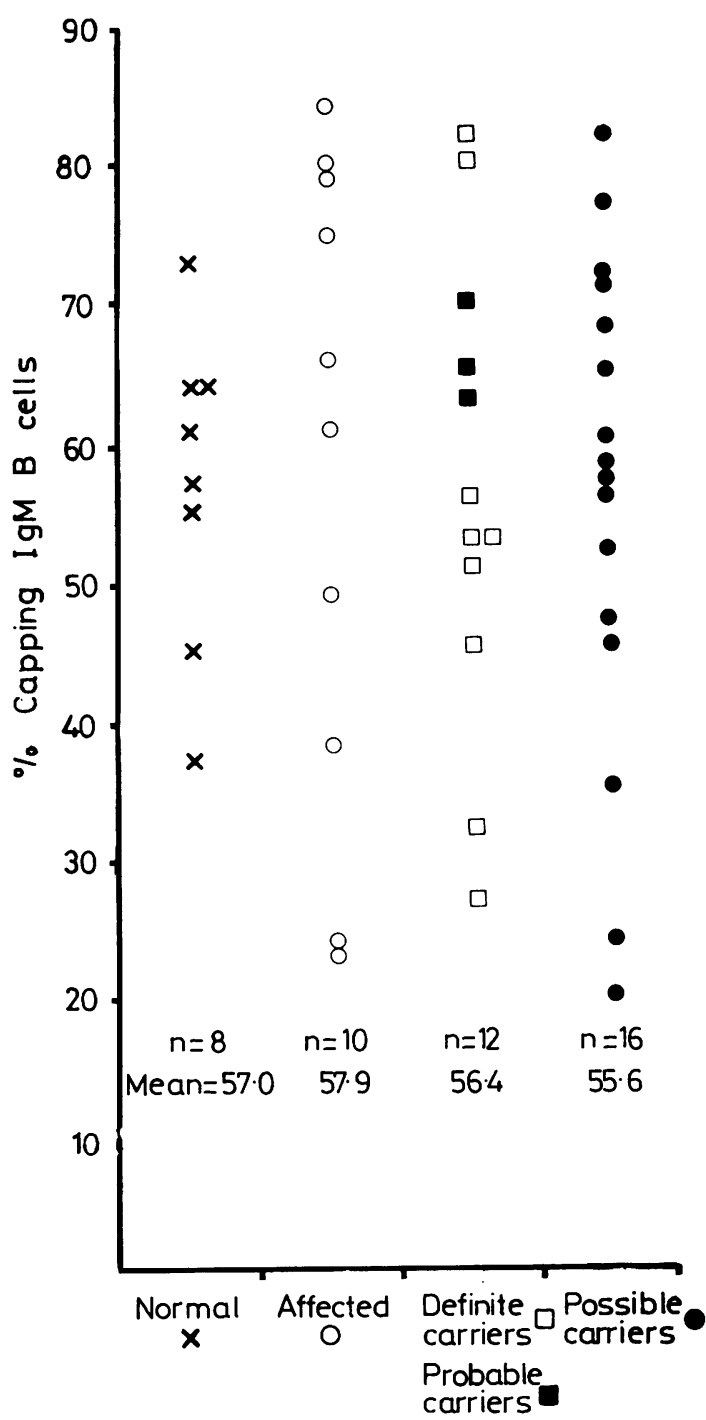

FIG 1 Distribution of percentage capping in $B$ lymphocytes in various clinical groups. 


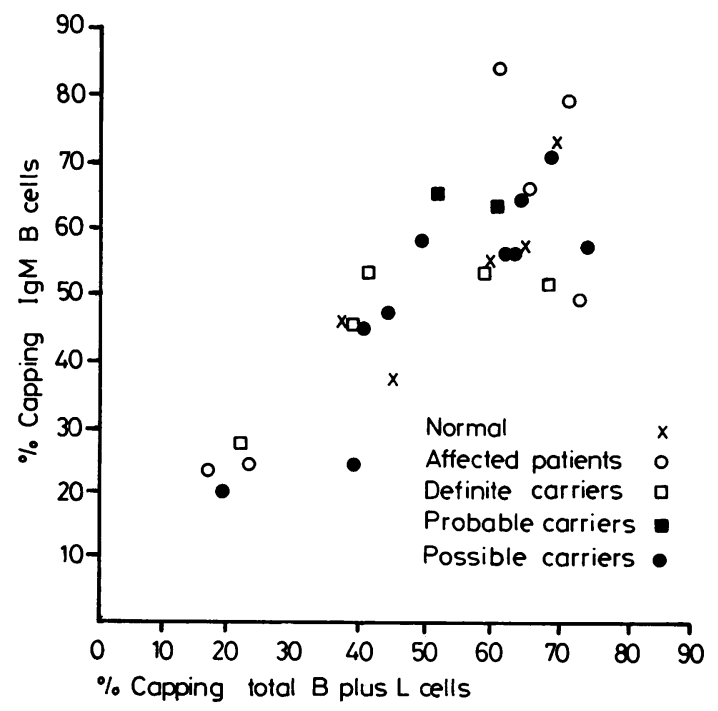

FIG 2 Comparison of distribution of percentage capping in IgM $B$ cells and in total $B+L$ cells in various clinical groups.

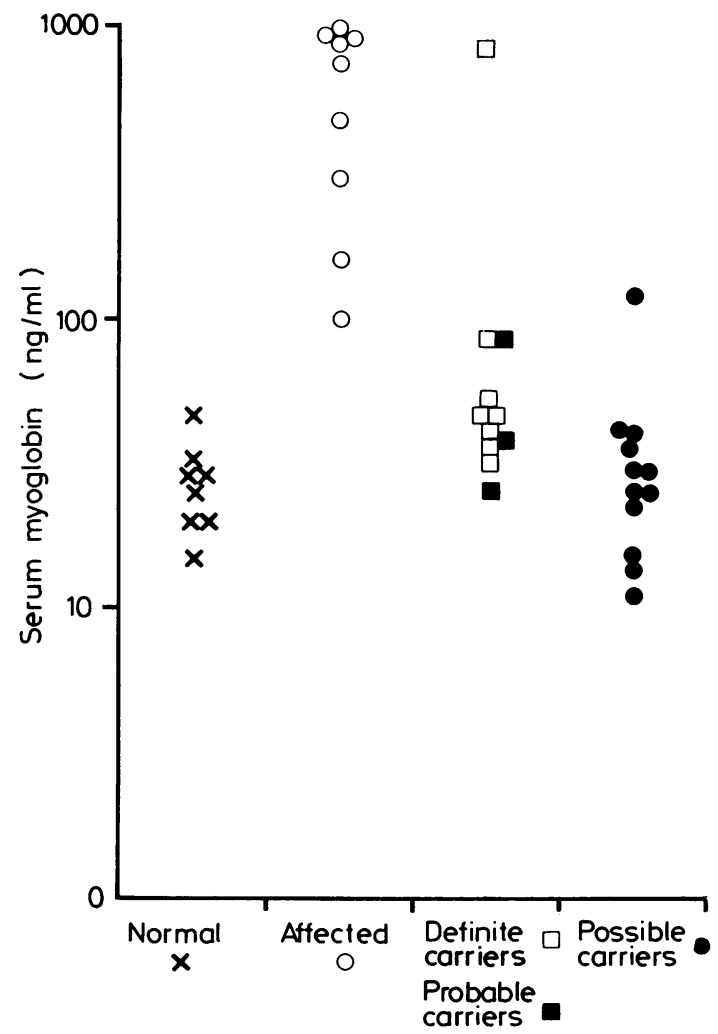

FIG 3 Serum myoglobin levels in different groups. Results are shown on a logarithmic scale.
The serum myoglobin levels in fig 3 show a very clear difference between patients and the other groups in most cases. In nine males with the disease the median was $750 \mathrm{ng} / \mathrm{ml}$ with a range of 152 to $920 \mathrm{ng} / \mathrm{ml}$. In eight definite carriers the median was $46 \mathrm{ng} / \mathrm{ml}$ and the range 35 to $840 \mathrm{ng} / \mathrm{ml}$. Twelve possible carriers had a range of 15 to $42 \mathrm{ng} / \mathrm{ml}$ and a median of $27.5 \mathrm{ng} / \mathrm{ml}$, whereas in eight controls the median was $26.5 \mathrm{ng} / \mathrm{ml}$ with a range of 14 to $48 \mathrm{ng} / \mathrm{ml}$.

Although the median in definite carriers was higher than in controls, there was considerable overlapping of results. Five of their myoglobin levels were lower than the highest of the controls, and six fell within our normal range.

SCK concentrations are shown in fig 4. All of the affected males showed markedly raised levels. None of the definite carriers had concentrations within the normal range, although the increases were much smaller than in the affected group.

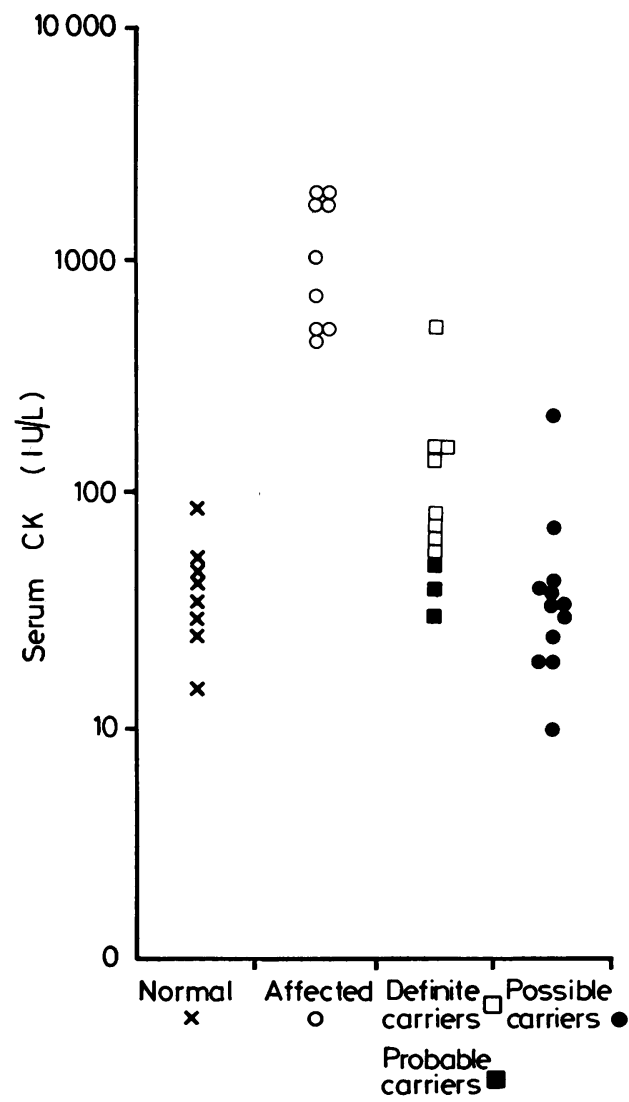

FIG 4 SCK concentrations in various clinical groups. Results are shown on a logarithmic scale. 


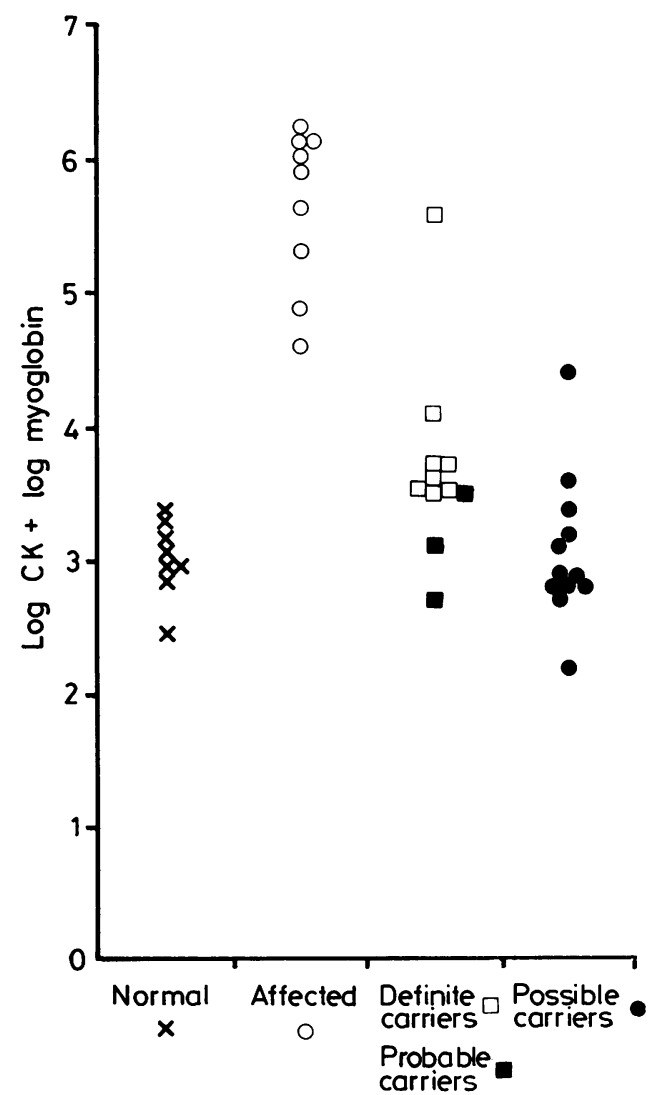

FIG 5 Log SCK + log myoglobin in the clinical groups.

Neither of the two with raised myoglobin levels had normal SCK values.

In fig 5 the logarithmically transformed results for SCK and myoglobin have been added and the overlap between the definite carriers and other groups is removed. This apparently improved differentiation between the groups may simply be a function of the numerical distribution of the figures and may disappear when greater numbers of patients are studied. Even if this does occur because of the distribution of the figures it may still be useful if it separates carriers from normal subjects.

\section{Discussion}

Pickard and his colleagues have stimulated a great deal of interest and the reported changes in $B$ lymphocytes could reasonably have been expected with a widespread membrane defect in Duchenne muscular dystrophy. However, it has not been possible to confirm a reduction in lymphocyte capping in the families studied in this report and there was no significant difference between patients, carriers, and controls. At this stage it is difficult to suggest any satisfactory explanation for this discrepancy but differences in technique would seem a possible explanation. Their report makes no reference to the presence of sodium azide in the polyvalent anti-immunoglobulin conjugate that they used, but it is our understanding that their material (supplied by Meloy Laboratories) does contain this material. Sodium azide can itself inhibit the capping phenomenon and we took care to remove this material from our system by dialysing the conjugates before use. It is possible that the use of an azide-containing conjugate could have impaired capping ability in their study but it is not clear why this should single out the patients with muscular dystrophy and the heterozygote carriers. Although their paper described the capping behaviour of ' $B$ lymphocytes', no distinction is made between lymphocytes bearing surface stable immunoglobulin, that is, B cells, and the lymphocytes bearing surface-labile $\mathbf{I g G}$, that is, $\mathrm{L}$ cells. ${ }^{12}$ However, in fig 2 the capping behaviour of IgM bearing B lymphocytes, that is, $\mathbf{B}+\mathbf{L}$ cells, is seen to correlate very closely with the capping behaviour of IgM bearing $\mathrm{B}$ lymphocytes. We have also been able to exclude phagocytic mononuclear cells in our evaluation. It occurred to us that the use of a water lysis step as used by Pickard et al might conceivably have affected capping behaviour but other studies that we have performed have not revealed any significant difference when cells are subjected to this method of erythrocyte removal.

Adornato and his colleagues ${ }^{11}$ measured myoglobin concentrations by a complement fixation technique which is less sensitive than the radioimmunoassay method used in the Nottingham series. This would account for the division of subjects into those with and those without myoglobinaemia, whereas we have been able to measure the lower levels of myoglobin normally present in the serum. We did not include the forearm ischaemic exercise test in these preliminary investigations. There does appear to be considerable day to day fluctuation in myoglobin levels, a fact commented upon by Adornato et al, and confirmation of some diurnal variation has been noted in our laboratory. Adornato et al also list a number of conditions in which myoglobinaemia may be found but none of these were present in our patients. SCK levels were single specimen estimations only although it is usual practice to take an average of three values. Despite this, this test seemed to be more helpful than myoglobin estimation.

Neither of these newly described investigations appears to allow better discrimination between 
carriers and controls than routine SCK estimations. It would be of considerable interest to have reports from other centres and serum myoglobin levels should be assessed in larger series of subjects. This will also help to determine if the addition of logarithmic values of SCK and myoglobin will prove to be of value.

Identification of carriers of DMD is an important aspect of the management of families in which this disease is segregating. In addition a number of affected males, probably as many as a third of the total, will be born to normal, non-carrier females and differentiation of these is essential for accurate counselling. There is need for more reliable maternal markers and advances in prenatal diagnosis of this disease makes the task an important and urgent one.

We thank the patients and families who took part in this study and the colleagues who referred patients to us. Health Visitors Miss S Stapleton and Miss V Hayes gave invaluable help in arranging for specimen collection. Our thanks are also due to Eurotope Ltd, London, who kindly supplied the kits for myoglobin assays, and to Miss J Saunders, AIMLS and Mr J H Ransom, FIMLS for technical assistance.

\section{References}

1 Editorial. Red cell deformability. Lancet 1978;2:1348-9.

2 Matheson DW, Howland JL. Erythrocyte deformation in human muscular dystrophy. Science 1974 ;184:165-6.
${ }^{3}$ Mokri B, Engel AG. Duchenne dystrophy: electron microscopic findings pointing to a basic or early abnormality in the plasma membrane of the muscle fiber. Neurology 1975;25:1111-20.

4 Butterfield DA. Electron spin resonance studies of erythrocyte membranes in muscular dystrophy. Acc Chem Res 1977;10:111-5.

5 Dubowitz V. Screening for Duchenne muscular dystrophy. Arch Dis Child 1976;51:249-51.

6 Satapathy RK, Skinner R. Serum creatine kinase levels in normal females. J Med Genet 1979;16:49-51.

7 Verrill HL, Pickard NA, Gruemer HD. Diminished cap formation in lymphocytes from patients and carriers of Duchenne muscular dystrophy. Clin Chem 1977;23: 2341-3.

8 Pickard NA, Gruemer HD, Verrill HL, et al. Systemic membrane defect in the proximal muscular dystrophies. $N$ Engl J Med 1978;299:841-6.

9 Tyler FH. Muscles, membranes and maternal markers. $N$ Engl J Med 1978;299:885-6.

10 Editorial. Lymphocyte capping and carrier detection in Duchenne muscular dystrophy. British Medical Journal 1978;2:1589-90.

11 Adornato BT, Kagen LJ, Engel WK. Myoglobinaemia in Duchenne muscular dystrophy patients and carriers: a new adjunct to carrier detection. Lancet 1978;2:499-501.

12 Horwitz DA, Garrell MA. Distinctive functional properties of human blood L lymphocytes: a comparison with $\mathrm{T}$ lymphocytes, B lymphocytes and monocytes. J Immunol 1977;118:1712-21.

Requests for reprints to Dr J S Fitzsimmons, Genetic Counselling Service, City Hospital, Hucknall Road, Nottingham NG5 1PB. 